ARTIGO ORIGINAL

\title{
“TDAH depois de grande?” Implicações da descoberta tardia do TDAH em uma estudante universitária
}

\section{“ADHD in adulthood?" Educational implications of the discovery of ADHD in a university student}

\author{
Thales Fabricio da Costa e Silva \\ Universidade Federal de Campina Grande, E-mail: thalespsic@gmail.com
}

Kevin Ferreira Corcino

Centro Universitário Uninabuco, E-mail: kevinfc@hotmail.com

\begin{abstract}
Resumo: O Transtorno de Déficit de Atenção e Hiperatividade (TDAH) é caracterizado como um padrão persistente de desatenção e/ou hiperatividade-impulsividade que impacta a vida de crianças, adolescentes e adultos. Na ausência de uma conduta adequada por parte de familiares e agentes escolares que lidam com crianças com TDAH, muitas destas terminam enfrentando desafios ao longo da vida, ultrapassando as tradicionais dificuldades identificadas na infância. Neste sentido, esta produção tem o objetivo de apresentar as implicações da descoberta tardia do diagnóstico de TDAH em um adulto, a partir do estudo de caso de uma universitária. As discussões partem do relato de experiência de um psicólogo que acompanhou a estudante em uma universidade pública federal. A análise deste caso revela os desafios educacionais enfrentados pela jovem desde os primeiros anos de escolarização até a formação universitária, bem como as fragilidades do processo de medicalização que atravessa a sua experiência de vida. $\mathrm{O}$ trabalho convida professores, familiares, psicólogos e outros agentes educacionais a pensarem o adequado manejo de casos de indivíduos que apresentem dificuldades de aprendizagem - sejam elas decorrentes de transtornos psicológicos e/ou outras problemáticas inerentes ao processo de escolarização - a partir de mecanismos de incentivo às potencialidades do sujeito.
\end{abstract}

Palavras-chave: Transtorno do déficit de atenção e hiperatividade. Dificuldades de aprendizagem. Medicalização. Psicologia escolar. Educação.

\begin{abstract}
Attention Deficit Hyperactivity Disorder (ADHD) is characterized as a persistent pattern of inattention and / or hyperactivity-impulsivity that impacts the lives of children, adolescents and adults. In the absence of proper conduct by family members and school agents who deal with children with ADHD, many of them end up facing challenges throughout their lives, overcoming the traditional difficulties identified in childhood. In this sense, this research aims to present the implications of the late discovery of the diagnosis of ADHD in an adult, from the case study of a university student. The discussions start from the experience report of a psychologist who accompanied the student at a federal public university. The analysis of this case reveals the educational challenges faced by the young woman from the first years of schooling to university education, as well as the weaknesses of the medicalization process that goes through her life experience. The work invites teachers, family members, psychologists and other educational agents to think about the appropriate case management of individuals who have learning difficulties - whether due to psychological disorders and / or other problems inherent to the schooling process - from incentive mechanisms to the subject's potential.
\end{abstract}

Keywords: Attention deficit hyperactivity disorder. Learning difficulties. Medicalization. School psychology. Education. 


\section{INTRODUÇÃO}

A escolarização entrelaça experiências para as mais diversas fases da vida do sujeito, permitindo a construção de um repertório de relações entre indivíduo, família, escola e meio em que habita. Como um lugar vivo, a escola pode oportunizar sabores e dissabores, visto a multiplicidade de indivíduos que a experimentam e as diversas formas como eles a percebem. Nesta seara, o processo de escolarização pode ser marcado por vivências producentes e/ou contraproducentes, e esta compreensão depende de fatores que, por vezes, estão alheios à própria escola, como é o caso das crianças com alguma dificuldade de aprendizagem.

Historicamente, a escola brasileira não foi pensada pela lógica do acesso igualitário - já que a construção do sistema educacional brasileiro se correlaciona com a formação da nação numa base escravista e de projetos de desenvolvimento desiguais (MEINERZ e CAREGNATO, 2011), o que levou inúmeros indivíduos a viverem processos de exclusão de forma explícita, a exemplo de pessoas pretas, pardas e indígenas, as que estão em vulnerabilidade socioeconômica e pessoas com deficiência. Somado a isso, percebe-se que a escola também foi lapidada numa base que não comportava os que distavam do padrão aceitável de aprendizagem.

Um projeto de escola pública para todos é recente no país, levando indivíduos a abrigarem uma escola despreparada para lidar com a diversidade existente, culminando com expressivos índices de dificuldades de permanência e baixo rendimento escolar. Entre os que figuram estes índices, ganham destaque aqueles que apresentam algum tipo de dificuldade de aprendizagem decorrentes de problemas psicológicos, tão disseminados e discutidas nos últimos anos.

O despreparo apontado faz com que, muitas vezes, a escola e seus agentes educacionais direcionam o olhar às limitações dos estudantes que possuem algum tipo de dificuldade de aprendizagem, em vez de trabalhar as potencialidades desses indivíduos - muitas vezes chegam a anular essas potencialidades. Isso pode ser explicado pelo que foi apontado por Pletsch (2009), ao abordar que, no Brasil, a formação de professores e demais agentes educacionais segue ainda um modelo tradicional, inadequado para suprir as necessidades dos estudantes em sua heterogeneidade, dificultando um processo educacional inclusivo. Tal problemática é acentuada quando este estudante apresenta traços de algum transtorno, como é o caso do Transtorno de Déficit de Atenção e Hiperatividade (TDAH).

Segundo o Manual Diagnóstico e Estatístico de Transtornos Mentais (DSM-5), da Associação Americana de Psiquiatria (APA, 2014), o TDAH é caracterizado como um padrão persistente de desatenção e/ou hiperatividade-impulsividade que interfere no funcionamento e no desenvolvimento do indivíduo.

Diante da falta de uma conduta adequada aos casos de TDAH em escolares, muitos destes indivíduos terminam enfrentando desafios ao longo da vida, ultrapassando as tradicionais dificuldades vividas na infância e adolescência. Na juventude, por exemplo, um indivíduo com TDAH, ao ingressar numa universidade, poderá encontrar dificuldades com o planejamento, a organização, a autorregulação de comportamento e cumprimento de tarefas, podendo interferir em seu desempenho acadêmico (SOUZA et. al., 2017; OLIVEIRA; DIAS, 2017; THOMAS et. al., 2015; GRAY et. al., 2014).

Neste sentido, este trabalho tem o objetivo de as implicações da descoberta tardia do diagnóstico de TDAH em um adulto, a partir do estudo de caso de uma universitária. Consiste na apresentação do caso de uma jovem de 24 anos, cursando o $3^{\circ}$ período de um curso de graduação em uma universidade pública federal, que procurou ajuda ao psicólogo da referida instituição no ano de 2019 e recebeu suporte profissional na busca de estratégias de superação das dificuldades em se manter no curso diante das características do TDAH.

Portanto, a apresentação deste caso se mostra relevante já que discute o TDAH numa etapa da vida que é pouco difundida pela literatura: a fase adulta (BARBOSA, 2017). Além disso, revela os desafios educacionais enfrentados pela jovem desde os primeiros anos de escolarização até a formação universitária, bem como do processo de medicalização que atravessa a sua experiência de vida. Por fim, o trabalho demonstra a importância do cuidado que os educadores devem ter desde as séries iniciais na identificação e manejo de casos de indivíduos que apresentem dificuldades de aprendizagem, sejam elas decorrentes de transtornos psicológicos e/ou outras problemáticas inerentes ao processo de escolarização.

\section{MATERIAL E MÉTODOS}

Este estudo de caso parte da experiência de um psicólogo atuante em um campus da referida instituição, que continuamente recebe demandas relacionadas ao processo de ensino-aprendizagem no ensino superior. A seleção deste caso se deu pela sua exclusividade frente aos outros casos atendidos pelos profissionais na instituição até aquele momento, o que pode ser explicado pelo caráter incomum do diagnóstico de TDAH em adultos, já que por muito tempo era considerado um diagnóstico estritamente infanto-juvenil. Ao longo desta seção, será apresentado um roteiro do manejo que o caso recebeu na instituição, revelando a importância da intervenção compartilhada e da adequada orientação ao estudante, que revelou substancial melhora quanto à gestão da sua demanda.

Inicialmente, cabe considerar que o estudo de caso, como propõe Galdeano et al. (2003), permite que o profissional observe, entenda, analise e descreva uma situação real, adquirindo conhecimento e experiência que podem ser úteis na tomada de decisão frente a outras situações. Embora a proposta deste estudo de caso não seja uma investigação aprofundada, densa e com viés clínico, a análise da problemática permite, a partir dos recursos utilizados, promover maior conhecimento acerca do tema. $\mathrm{O}$ relato presente neste trabalho considerará as informações obtidas no ano de 
2019 e, portanto, serão tratadas no tempo passado ao longo desse texto, não revelando dados atuais e/ou futuros.

A estudante, doravante identificada com o pseudônimo Maria, 24 anos, solteira, residia com os pais na mesma cidade em que estudava. Estava no $3^{\circ}$ período de um dos cursos de graduação da instituição, porém, já possuía uma graduação concluída. À época dos atendimentos, trabalhava em um órgão público em um turno oposto ao dos estudos, tendo um turno disponível para realizar outras tarefas. Procurou o psicólogo com o intuito de receber orientação e auxílio no enfrentamento às dificuldades emocionais vivenciadas no momento; sua decisão em procurar o profissional se deu pela facilidade em acessá-lo na própria instituição escolar e também como um complemento ou alternativa ao tratamento psiquiátrico ao qual estava passando. Como a atuação do psicólogo escolar não está relacionada ao campo clínico e com propósito diagnóstico, foi necessário esclarecer a estudante sobre o papel deste profissional no espaço universitário.

A atuação do psicólogo no contexto escolar, como aponta Antunes (2008), é focada no processo de escolarização, tendo como objeto a escola e as relações que aí se estabelecem. Partindo desta compreensão, é importante superar a prática histórica do psicólogo como um clínico dentro do espaço escolar, senão, como apontam Prediger e Silva (2014), continuarão sendo comuns os relatos de profissionais que mencionam as constantes demandas de ajustamento que a escola os coloca, persistindo um modelo de patologização das questões escolares que se expressam pela expectativa de uma intervenção individualizada.

Entre as diversas possibilidades de atuação do psicólogo no contexto escolar, ainda é comum a prática da escuta às queixas relacionadas à vivência escolar, especialmente por parte dos estudantes. No entanto, essa perspectiva talvez provenha do fato de que, historicamente, como apontou Andaló (1984), a área escolar se caracterizou como um desmembramento da área clínica, o que gerou a visão de uma "Psicologia Escolar Clínica". A fim de superar tal ideia, precisa-se pensar a atuação do psicólogo a partir de uma postura analítica e de intervenção para além do âmbito individual, abrangendo outras vivências e fenômenos atrelados a este espaço: objetivos institucionais, práticas pedagógicas e relações interpessoais são alguns deles.

Nestas condições, o olhar do psicólogo acerca da escola se amplia, reconhecendo que o processo educativo e os desdobramentos psicológicos se dão em várias dimensões (individual, grupal, institucional e social), sendo o psicólogo um profissional limitado e que não consegue dar conta de todas essas nuances (MARTINS, 2003). Assim, é mister destacar que a atuação em equipe e o compartilhamento de fazeres e demandas são aspectos inerentes a atuação do psicólogo no âmbito escolar e, para o caso abordado neste trabalho, não seria diferente.

Feito este preâmbulo, cabe continuar a apresentação do manejo do caso em questão. A estudante foi atendida pelo psicólogo em quatro encontros, durante o ano de 2019. A partir do acolhimento e escuta da demanda apresentada, deu-se início ao caminho investigativo que se desdobrou nas intervenções feitas pelo profissional. Desta forma, o primeiro encontro ocorrido com Maria teve o objetivo de acolher sua demanda e realizar a coleta de dados referentes a queixa apresentada, bem como sobre a sua história de vida, incluindo aspectos familiares, sociais e escolares. A coleta de dados, feita através de entrevista livre e observação, seguiu por mais um encontro na semana seguinte. $O$ terceiro e o quarto encontro serviram de acompanhamento do caso diante das decisões tomadas colaborativamente. Os resultados deste roteiro serão apresentados na seção a seguir.

\section{RESULTADOS E DISCUSSÃO}

Com a queixa inicial de dificuldade de ajustamento à rotina acadêmica em decorrência de dificuldades psicológicas, a estudante procurou o psicólogo para receber atendimento individual clínico, no entanto, conforme já apresentado, por descaracterizar o trabalho do profissional no contexto educacional, a estudante foi devidamente esclarecida acerca do fazer profissional. Ante o acolhimento e escuta realizados, Maria descreveu o percurso que fez quanto aos cuidados em saúde mental a respeito do seu caso. Já havia passado por dois psiquiatras, que a diagnosticaram com transtorno de ansiedade (mais precisamente, Transtorno Obsessivo Compulsivo TOC) e depressão e, por tanto, já havia feito uso de medicação psicotrópica; como não havia identificado melhora significativa, suspendeu (por conta própria, o que não é indicado) o uso das medicações.

Por trazer uma queixa que incluía transtornos previamente diagnosticados, o psicólogo buscou investigar o histórico do quadro e quais as afetações na vida diária da estudante. Ao descrever o quadro sintomatológico, a estudante citou, como os principais traços, "constante inquietação, algumas manias, tarefas inacabadas, pouca concentração, pensamentos flutuantes, distração e dificuldade em estabelecer rotina".

Em um estudo com estudantes universitários, Oliveira e Dias (2017) apontaram que as principais dificuldades de estudantes universitários com TDAH estão relacionados à gestão da concentração às aulas e a outros estímulos, relacionamento com colegas e professores, raciocínio, desenvolvimento de autonomia e procrastinação. $\mathrm{Na}$ mesma direção, Lopes et al. (2005) citam que, em adultos, o quadro de TDAH se manifesta nos seguintes traços: dispersão e desatenção, erros repetidos, perder coisas, não recordar o que acabou de ler, pergunta várias vezes a mesma coisa e evita leitura que não seja de seu interesse específico, adormece ou desliga diante de assuntos que não lhe interessam diretamente, dedica-se a trabalhos que exijam pouca atenção e concentração. Pelo exposto, observa-se que a estudante que ilustra essa experiência apresenta traços semelhantes aos apontados em outros estudantes. 
Em decorrência da investigação realizada, seguem alguns relatos da estudante, devidamente adaptados a esse modelo de produção.

Desde pequena fui muito danada na escala, sempre apresentava dificuldades no comportamento e isso era motivo pra ser mal vista por professores e familiares. Costumava ser muito rápida na execução das tarefas, para depois ficar mexendo ou conversando com os amigos. Embora eu nunca estudasse, sempre tirava boas notas, inclusive, minha mãe e meus professores chegavam a duvidar da minha capacidade, julgando que eu passava colando. No ensino médio era da mesma forma. $\mathrm{Na}$ faculdade, embora já adulta, também me comporto de forma muito inquieta; não consigo ficar em sala de aula e assistir as aulas por completo, então sempre invento algum motivo para estar fora da sala. Além disso, meu celular está sempre ligado, pois é muito difícil acompanhar a aula do professor, sentada e prestando atenção.

As dificuldades comportamentais descritas pela aluna incluíam permanecer quieta, não se concentrar nas tarefas, ficar sempre se mexendo (se ficar muito tempo parada), entre outros prejuízos decorrentes deste traço no seu dia a dia. Mencionava, ainda, que tais dificuldades se repetiam em outros espaços, que não só a universidade, como no trabalho, quando estava com amigos, em casa ou em outros lugares.

Outra dificuldade apresentada pela jovem estava relacionada à realização profissional.

Sempre quis cursar Medicina, mas diante da dificuldade de entrar no curso e pelas pessoas duvidarem da minha capacidade, devido ao meu jeito, achei que não conseguiria e nunca tentei. Cheguei a passar em outro curso na área da saúde, mas não cursei porque meu pai não me deixou sair de casa. Então terminei optando por esse. Nunca gostei do curso, concluí apenas para mostrar aos meus pais a minha capacidade. Pra mim foi muito difícil criar uma rotina de estudo, pois não era acostumada com isso; a minha sorte foi um amigo que ficava me pressionando a dar conta dos estudos. Costumo me inscrever em concursos públicos, mas nem sempre vou fazer as provas, justamente porque não tenho rotina de estudos e não me sinto preparada.

A decisão profissional é uma escolha que marca profundamente a vida de um indivíduo. Neste caso, as decisões de Maria foram influenciadas tanto por agentes externos quanto pela forma de conceber sua própria capacidade intelectual - influenciada pela forma como os outros a viam. Cabe considerar que este é um desafio que ainda se mantinha em sua vida até aquele período, tendo em vista que, após o término do primeiro curso de graduação (na área de humanas), iniciou outro curso na área das ciências exatas, o qual cursou apenas um semestre e desistiu; assim, terminou optando posteriormente pelo curso em que estava matriculada àquela época.

$\mathrm{Na}$ continuidade do relato da sua história, mencionou a presença de manias como outra característica do seu quadro.

Tenho algumas manias, como se fosse um 'TOC'. Geralmente são manias bestas, às quais me apego para ficar ocupada, quando não tenho o que fazer. Como termino não fazendo outra coisa, percebo que o único prejuízo que tenho é o tempo perdido com estas manias.

Ao investigar as possíveis manias, constatou-se que elas não surgiam de pensamentos obsessivos e não tinham uma continuidade, visto que cessavam sempre que encontrava algo mais producente ou atrativo a ser feito. Não correlacionava medos ou perigos associados ao comportamento e não identificava outros prejuízos significativos decorrentes destas atitudes. Em suma, as manias nomeadas por ela funcionavam como tarefas que lhe prendiam a atenção em momentos de ociosidade.

Outro ponto importante trazido pela estudante diz respeito à dificuldade de concluir tarefas e projetos. Apontou em seu relato:

Tenho uma grande dificuldade em concluir atividades longas ou qualquer coisa que queira aprender. Por exemplo, já iniciei aula de violão e logo deixei; sempre entro na academia, mas não vou mais que algumas semanas; entrei na natação, mas logo depois deixei de ir; até o inglês, que seria muito importante pra mim, não consegui concluir.

Dos exemplos apresentados, depreendeu-se, durante a investigação junto a estudante, que a dificuldade em se manter no projeto não tinha relação direta com a natureza da atividade (pois todas elas eram atividades prazerosas para Maria), mas devido ao caráter rotineiro de cada atividade: Maria apontava que era chata a repetição dos exercícios da academia, faltava paciência para seguir o passo a passo nas aulas de violão e inglês e tinha dificuldade em seguir os horários marcados e exercícios na natação, sendo alguns exemplos dos aspectos que dificultavam a sua vivência com essas tarefas.

Diante do exposto, um questionamento que se lançava frente a este traço comportamental é "como a estudante gerenciava sua rotina de cinco anos no seu curso de graduação"? Pelo que foi apresentado, a possível resposta estava no fato de a jovem sempre ter conseguido gerir o curso ao seu modo: embora não 
faltasse, não assistia as aulas integralmente, saía muito da sala de aula, conversava bastante com colegas, ficava pelos corredores, utilizava muito o celular, ou seja, ela ditava a organização da sua rotina no curso e "levava-o com a barriga", como a própria aluna chegou a mencionar; contribuía para este comportamento o fato de ela não gostar do curso, fazendo-o, tão somente, como resposta aos julgamentos dos outros acerca da sua competência.

Dados sobre a vida familiar e social revelavam que a jovem tinha boa convivência com os pais, amigos e colegas de faculdade; considerava que a família possuía boas condições financeiras, o que a permitia desfrutar de experiências desejadas, como viagens e saídas nos finais de semana com os amigos. Mencionava que nas viagens dificilmente apresentava os sintomas mencionados, o que pode revelar o caráter de interesse pela atividade e pelas novidades que a viagem proporcionava, facilitando o desfrute deste momento. Segundo Oliveira et al. (2018), os sinais do TDAH podem ser minimizados pelo controle rígido do sujeito, quando este se encontra em um ambiente novo ou quando está envolvido em atividades que despertam seu interesse, como era o caso das viagens feitas por Maria.

Quanto ao trabalho, apontava que não sentia muito prazer em executá-lo por dois motivos principais: baixo retorno financeiro e atividades repetitivas; afirmava que se mantinha nele por ser de provimento efetivo e carga horária reduzida. Como tinha grande interesse em se ausentar dele e conquistar um que lhe desse um maior retorno financeiro e realização pessoal, considerava a possibilidade de iniciar os estudos para novos concursos com brevidade.

No que diz respeito à rotina diária, mesmo dispondo de um turno livre, a estudante mencionava grande dificuldade em preencher este horário com atividades producentes. Geralmente ficava navegando na internet, em sites que considerava improdutivos, em decorrência da grande resistência em parar para estudar ou fazer qualquer outra tarefa sistemática.

Diante do relato apresentado, o psicólogo considerou as inúmeras informações trazidas e, com vistas a ampliar o entendimento deste histórico, sugeriu que a estudante conversasse com familiares e amigos a respeito do seu comportamento de infância e adolescência, em casa e na escola, a fim de obter um olhar de outros indivíduos. Tal compromisso ficou acordado no encerramento do primeiro encontro. $\mathrm{O}$ pedido se deu em virtude do histórico de desatenção e hiperatividade relatado e que carecia de outras fontes de informação. Este pedido se amparou nas discussões de Dias et al. (2007), que apontou que o diagnóstico de TDAH na vida adulta se baseia primariamente no relato do próprio adulto que, frequentemente, pode apresentar dificuldades para recordar o histórico de TDAH durante a infância, o que suscita outras fontes de informações para além do autorrelato.

$\mathrm{O}$ segundo encontro foi marcado pela apresentação da experiência que teve em conversas com a mãe e algumas amigas a respeito das vivências de infância e adolescência. Da conversa com a mãe e amigas, obteve as seguintes informações: sempre apresentou inquietação, desatenção, dificuldade em seguir regras em casa e na escola, dificuldade em executar planos estabelecidos (inclusive, costumava mudar os planos com frequência), além de ser muito criativa, inteligente e ter facilidade em aprender. Deste modo, identificou-se a historicidade do seu quadro de dificuldades comportamentais, perceptível pela própria estudante e pelos demais indivíduos que convivem com ela.

Cabe destacar que, neste segundo encontro, a estudante ressaltou a frustração decorrente da dificuldade explícita e onerosa de não conseguir executar seus planos, o que gerava muito desconforto emocional, atribuindo, especial motivação, à idade avançada e cobranças arroladas.

Os dois encontros funcionaram como um espaço de escuta, acolhimento e investigação da demanda apresentada, auxiliando a estudante a compreender o diagnóstico sugerido durante o tratamento psiquiátrico. Neste sentido, havia uma grande possibilidade de Maria não vivenciar um TOC ou transtorno depressivo (como havia sido sugerido pelos psiquiatras), pois os traços apresentados indicavam a hipótese de um quadro de TDAH. Quando foi psicoeducada a respeito dessas considerações por parte do psicólogo, a estudante apontou que nunca imaginou que suas características tivessem relação com esse quadro, especialmente agora "depois de grande", além do que sempre imaginou que o seu problema fosse ansiedade e depressão. Essas informações vão ao encontro das considerações feitas por Lopes, Nascimento e Bandeira (2005), ao citarem que adultos com TDAH não são críticos quanto a suas dificuldades de atenção e poucos se dão conta do problema; além disso, os traços apresentados pela estudante podem ser justificados pelos achados de Silva (2014), que identificou que universitários com TDAH apresentam mais adversidades em relação a seus pares não TDAH, como mais sintomas depressivos, mais prejuízo acadêmico e pior qualidade de vida, o que pode gerar semelhanças entre os diversos quadros de saúde.

Longe de pretender uma intervenção clínica, o auxílio do profissional de psicologia da universidade pautou-se na perspectiva de acolher a estudante em sua demanda e auxilia-la no percurso acadêmico a partir das demandas apresentadas e da mediação com as diversas instâncias institucionais e fora da instituição, reconhecendo e deixando-a lúdica, desde o primeiro momento, sobre a importância de uma intervenção compartilhada. Além das orientações psicológicas para melhor condução da vida acadêmica, a estudante necessitava de uma nova avaliação psiquiátrica, tendo em vista a possibilidade de emergir um novo diagnóstico, além da conduta anterior em abandonar a medicação que fazia uso; ademais, uma intervenção psicoterapêutica poderia contribuir com o caso, já que, além de relatar interesse neste tipo de trabalho, a estudante apresentava características elegíveis à intervenção clínica.

Para ilustrar a suspeita do psicólogo escolar a respeito do provável diagnóstico da estudante, são apresentados no quadro 1 os cinco critérios diagnósticos estabelecidos no DSM-5 (APA, 2014) 
para o TDAH em adultos: cinco ou mais sintomas de desatenção ou cinco ou mais sintomas de hiperatividade/impulsividade; alguns sintomas presentes antes dos 7 anos; algum prejuízo decorrente dos sintomas presente em dois ou mais ambientes (por exemplo, no trabalho e em casa); evidências claras de prejuízo significativo ao funcionamento social, acadêmico ou ocupacional; os sintomas não ocorrem exclusivamente no decorrer de um transtorno de desenvolvimento generalizado, esquizofrenia ou outro transtorno psicótico, e não são melhor explicados por outro transtorno mental (por exemplo, transtorno de humor, transtorno de ansiedade, transtorno dissociativo ou transtorno de personalidade).

Quadro 1 - Sintomas de Desatenção e de Hiperatividade/Impulsividade para o diagnóstico de TDAH

\begin{tabular}{|c|c|}
\hline Sintomas de Desatenção & Sintomas de Hiperatividade/Impulsividade \\
\hline $\begin{array}{c}\text { Frequentemente deixa de concentrar atenção nos } \\
\text { detalhes ou comete erros por descuido em atividades } \\
\text { diversas. }\end{array}$ & $\begin{array}{c}\text { Frequentemente mexe as mãos ou os pés, ou se move na } \\
\text { cadeira. }\end{array}$ \\
\hline $\begin{array}{c}\text { Frequentemente tem dificuldade de manter a atenção } \\
\text { em tarefas. }\end{array}$ & $\begin{array}{c}\text { Frequentemente levanta da cadeira em situações em } \\
\text { que é necessário permanecer sentado. }\end{array}$ \\
\hline $\begin{array}{c}\text { Frequentemente parece não escutar quando alguém lhe } \\
\text { dirige a palavra diretamente. }\end{array}$ & $\begin{array}{c}\text { Frequentemente circula no ambiente, em situações nas } \\
\text { quais isso é inadequado. }\end{array}$ \\
\hline $\begin{array}{c}\text { Frequentemente não segue instruções e deixa de fazer } \\
\text { tarefas (não por recusa ou não entender as instruções). }\end{array}$ & $\begin{array}{c}\text { Frequentemente tem dificuldade de se envolver } \\
\text { tranquilamente em atividades de lazer. }\end{array}$ \\
\hline $\begin{array}{c}\text { Frequentemente tem dificuldade de organizar tarefas e } \\
\text { atividades. }\end{array}$ & $\begin{array}{c}\text { Frequentemente está em movimento ou age "como se } \\
\text { tivesse um motor ligado". }\end{array}$ \\
\hline $\begin{array}{c}\text { Frequentemente evita, não gosta ou reluta em } \\
\text { envolver-se em tarefas que demandem esforço mental } \\
\text { prolongado. }\end{array}$ & $\begin{array}{c}\text { Frequentemente fala em excesso. } \\
\text { Frequentemente perde coisas que são necessárias para } \\
\text { realizar tarefas ou atividades. }\end{array}$ \\
\hline $\begin{array}{c}\text { Frequentemente é facilmente distraído com estímulos } \\
\text { externos. }\end{array}$ & $\begin{array}{c}\text { Frequentemente fala sem pensar ou responde antes da } \\
\text { pergunta ter sido finalizada. }\end{array}$ \\
\hline $\begin{array}{c}\text { Frequentemente é esquecido com atividades } \\
\text { cotidianas. }\end{array}$ & $\begin{array}{c}\text { Frequentemente tem dificuldade de esperar a sua vez. } \\
\text { Fremente interrompe outras pessoas ou é } \\
\text { invasivo. }\end{array}$ \\
\hline
\end{tabular}

Fonte: APA (2014)

Diante da ilustração feita e a identificação de todos os critérios para esta hipótese diagnóstica, o psicólogo escolar e a estudante, de forma colaborativa, reconheceram a necessidade de uma nova avaliação psiquiátrica e a possibilidade do cuidado compartilhado com um terceiro profissional: o psicólogo clínico, ficando a cargo da estudante a busca por este profissional com o devido suporte do psicólogo escolar.

O terceiro encontro, que se seguiu após a avaliação médica, revelou novos aspectos da condução do quadro. O psiquiatra considerou a hipótese de TDAH e prescreveu cloridato de metilfenidato, mais conhecido como Ritalina ${ }^{\circledR}$. Tal conduta médica fortalece o crescimento da prescrição e uso deste tipo de medicação no Brasil que, como apontam Oliveira et al. (2016), teve um aumento de $180 \%$ na comercialização entre os anos de 2009 e 2013.

Neste cenário, faz-se extremamente necessário discutir o movimento de "medicalização" observado nos últimos anos, em especial no contexto educacional, em que inúmeros indivíduos são responsabilizados pelo fracasso escolar diante das suas condições de saúde. Conforme aponta Negreiros et al. (2016), há a crença enraizada de que o uso de medicamentos pode ser a solução da defasagem do ensino, baseada em saberes médicos, que cooperam com a ideia reducionista, biologizante e patologizante de que o aluno carrega problemas que dificultam sua aprendizagem e que o mesmo deve ser tratado. Este movimento de "medicalização do aluno" por vezes funciona como uma justificação das atuais problemáticas que perfazem o contexto escolar, esquivando a instituição de suas responsabilidades.

Considerando o caso de Maria, em toda a sua vida, mesmo sem um diagnóstico preciso, sempre foi alvo de um discurso medicalizante, reduzindo-a a única responsável pelas suas dificuldades de ajustamento à rotina escolar. Embora tenha demonstrado em sua história de vida escolar/acadêmica resultados positivos em suas notas, a rotulação frente ao seu comportamento acarretou problemas de autoestima e autoimagem. Nos últimos anos, depois de consultar profissionais de saúde, o desconforto emocional se acentuou, visto que, mesmo com diagnósticos que a levavam ao uso de medicação psicotrópica como a melhor estratégia, estava refém de uma experiência emocional que a tornava "impotente" e lhe proporcionava um grande questionamento: "por que não consigo me curar?" - pergunta que costumava se fazer.

Como foi discutido por Barbosa (2017), por mais que cada estudante com TDAH gere sentidos subjetivos próprios em suas trajetórias escolares e acadêmicas, percebe-se a emoção permeando todos os seus espaços relacionais, sejam estes dentro ou fora da 
escola e da universidade, o que requer que professores, por exemplo, considerem essas singularidades dos estudantes quando formularem as metodologias a serem aplicadas no processo de ensino-aprendizagem.

É notório que considerar a medicação como a única saída inviabiliza a procura de outras alternativas pelo sujeito. Ademais, mascara outras fragilidades do quadro e desvia a responsabilidade de outros agentes, como a família e o próprio sistema educacional que, neste caso, também estava despreparado para lidar com a demanda da aluna, quando da sua vivência escolar. Um dado que ilustrava bem essa realidade era a frequência com que a família de Maria era convocada à escola para receber advertências e tentar resolver o problema comportamental da filha.

Além do exposto, ainda como resultado do terceiro encontro, a estudante mencionou que passou a se reconhecer nas características deste quadro, buscando investigar as particularidades do TDAH em adultos. Como forma de conseguir suporte, iniciou contatos com grupos de apoio, trocando experiências com outros jovens e adultos que também vivenciavam esta condição, mencionando que este novo momento lhe trouxe alívio emocional, tendo em vista a diminuição do sentimento de culpa e incapacidade. Para ela, a culpada sempre era ela mesma por não conseguir obter êxito nos planos que traçava, bem como nas dificuldades diárias, característica que era fortalecida na fala de familiares, professores e amigos.

$\mathrm{O}$ quarto encontro, que ocorreu algumas semanas após o terceiro, foi o desfecho momentâneo deste acompanhamento inicial. Também funcionou como um momento de escuta e devolutiva, no qual a estudante mencionou que, embora o uso da medicação estivesse melhorando o seu nível de atenção e rendimento nas tarefas, acreditava que estaria afetando seus traços de ansiedade (possivelmente fez essa interpretação em decorrência dos efeitos adversos comuns ao uso da medicação), o que gerava um grande questionamento pessoal acerca da necessidade do seu uso; neste sentido, foi motivada a manter o acompanhamento médico e seguir as orientações profissionais de uso da medicação.

Levando em consideração a necessidade de olhar para o quadro para além do perfil sintomatológico, mas também reconhecendo a importância do investimento no adequado manejo dos traços característicos do TDAH sem necessariamente estar sob efeito medicamentoso, foram discutidas algumas possibilidades de intervenção e introdução de novos hábitos que proporcionassem mais prazer e qualidade de vida à aluna, considerando, acima de tudo, a boa convivência com o curso.

Quanto a isso, era imprescindível que o psicólogo realizasse uma intervenção institucional, especialmente com os professores e a coordenação do curso ao qual a estudante estava matriculada, tendo em vista as implicações associadas; a ação foi realizada em formato de reuniões compartilhadas, dias após a conclusão do breve acompanhamento, com a presença de coordenadores de curso e alguns professores. Em que pese a importância da intervenção a nível institucional, era visível o quanto havia dificuldades por parte da equipe de professores para elaborar estratégias didáticas direcionadas ao atendimento das necessidades educacionais da estudante, o que requereu, naquele momento, se reportar à equipe de suporte pedagógico junto a Reitoria para orientações. Ficou agendado um momento de capacitação profissional junto aos professores do campus, sob a responsabilidade da Pró-Reitoria de Ensino da instituição.

Para finalizar a descrição dos resultados deste caso, cabe apresentar os dados obtidos em contatos realizados dois meses depois deste breve acompanhamento. Transcorrido este período, a estudante mencionou os pontos positivos em pertencer ao grupo de apoio numa rede social, em que vinha aprendendo com os pares como vivenciar e superar as dificuldades decorrentes do quadro de TDAH.

A troca de experiência me fez reconhecer que o meu problema não é o pior nem o maior que o de outras pessoas e também não mais o utilizo como justificativa para me acomodar. As orientações recebidas pelo psicólogo me ajudaram a tirar um peso das costas, pois eu nunca tinha uma certeza do que ocorria comigo e terminava não sabendo lidar com o meu problema; vivia tomando remédios que não me faziam melhorar de verdade e só agora, depois de entender o que passei todos esses anos, tenho aprendido a administrar melhor o meu problema.

Como resultados do percurso realizado pela estudante nos últimos meses, ela mais uma vez havia abandonado a medicação, mas estava procurando outro médico para uma nova avaliação - e sondar se havia a necessidade de introduzir nova medicação. Começou a frequentar aulas de pilates - que estavam lhe fazendo muito bem - e iria iniciar um tratamento de acupuntura. Quanto à graduação, resolveu trancar o curso assim que concluísse o atual semestre em que estava matriculada, tendo em vista que não era um curso que queria para a sua vida. Além disso, decidiu que iria pedir uma licença sem remuneração do trabalho para poder se dedicar aos estudos para concurso público em uma área que lhe desse mais rendimento financeiro e satisfação pessoal. Por fim, de modo geral, afirmou se sentir muito melhor consigo mesma, com maior domínio sobre o quadro e maior produtividade nas tarefas do dia a dia.

Embora o relato deste caso não seja fruto de uma avaliação tipicamente clínica, mas da análise de um psicólogo escolar que atendeu a estudante, os breves dados apresentados podem contribuir para ampliar as discussões sobre o tema e, assim como asseverou Barbosa (2017), os estudos que abordam essa temática podem contribuir para uma melhor compreensão do sujeito com traços e/ou diagnóstico de TDAH, permitindo reflexões sobre a emergência de um olhar sobre o transtorno para além da patologia, como a importância dos aspectos emocionais no processo de ensino-aprendizagem, o (não) lugar do diagnóstico na 
construção de estratégias pedagógicas e um olhar menos medicalizante ao sujeito nas instituições de ensino e na sociedade como um todo.

\section{CONCLUSÕES}

As pesquisas que discutem o TDAH em adultos no Brasil ainda são poucas (BARBOSA, 2017), especialmente as que direcionam a atenção à vivência de estudantes universitários. Diante disso, o estudo do caso apresentado contribui para o fortalecimento da pesquisa e intervenção neste contexto, tendo em vista as implicações que o TDAH apresentou na vida de Maria.

O despreparo da família e dos agentes educacionais em lidar com as manifestações comportamentais inerentes ao quadro, fez com que Maria enfrentasse desafios em todas as fases de escolarização, sendo considerada, muitas vezes, a única responsável pelas dificuldades enfrentadas, notadamente rotulada de desinteressada e trabalhosa. Ademais, quando dos diagnósticos recebidos, teve que carregar o peso do rótulo de uma adolescente/jovem com TOC e depressão. Nesse ínterim, a medicalização demarcou processos de vida escolar e social, mas não a ensinou a lidar com os sintomas e traços comportamentais que apresentava.

O diagnóstico tardio de TDAH, não por simples anseio de rotular, mas com o intuito de orientar o manejo do quadro e da vida de Maria, demonstra o quanto ainda há despreparo da família e da escola em lidar com este sujeito que não corresponde às expectativas de "ser normal". Depois de anos de um "não saber o que tenho", de diagnósticos (e seus respectivos tratamentos medicamentosos) e de múltiplas vivências escolares, é visível o quanto Maria foi marcada subjetivamente. Porém, com o auxílio profissional, a estudante passou a "se identificar/se encontrar", utilizando as suas próprias estratégias (algumas orientadas profissionalmente) de enfrentamento e melhor vivência do quadro.

É imperioso destacar, mesmo diante das fragilidades vividas pela jovem, os sucessos obtidos no âmbito educacional (boas notas e diversas aprovações) que, contrariando o que geralmente se difunde sobre o TDAH, apontam a necessidade de construir mecanismos de incentivo às potencialidades do sujeito e não as suas fraquezas. Nesta seara, é imprescindível que os educadores (professores e familiares) se espelhem em casos como este e os apresentados em outras pesquisas, que se tornam subsídio para reflexão da temática, ainda pouco difundida nos espaços escolares, de formação de professores e ambientes familiares.

Por fim, considerando que a natureza clínica do diagnóstico e tratamento de casos de transtorno mental e outras condições de saúde que levem ao desenvolvimento de dificuldades de aprendizagem não é função do psicólogo escolar, ressalta-se que este trabalho atingiu o intuito de fomentar a discussão sobre o tema, com especial destaque ao movimento de medicalização do aluno constatado na atualidade. Deste modo, ao mesmo tempo em que se torna relevante a produção e publicação de outros trabalhos que envolvam o TDAH em adultos, é imprescindível que psicólogos, educadores, familiares e outros agentes envolvidos no processo de escolarização contribuam de forma significativa para o máximo desenvolvimento educacional dos indivíduos, respeitando as suas singularidades.

\section{REFERÊNCIAS}

AMERICAN PSYCHIATRIC ASSOCIATION. Manual Diagnóstico e Estatístico de Transtornos Mentais: DSM-5. Tradução: Maria Inês Corrêa Nascimento [et. al.]; revisão técnica: Aristides Volpato Cordioli [et. al.]. - 5. ed. - Porto Alegre: Artmed, 2014.

ANDALÓ, C. S. A. O papel do psicólogo escolar. Psicologia, ciência e profissão, v. 4, n. 1, p. 43-7, 1984.

ANTUNES, M. A. M. Psicologia Escolar e Educacional: história, compromissos e perspectivas. Revista Semestral da Associação Brasileira de Psicologia Escolar e Educacional, São Paulo, v. 12, n. 2, p. 469-75, 2008.

BARBOSA, F. J. S. A subjetividade do estudante universitário diagnosticado com TDAH. 2017. $92 \mathrm{f}$. Dissertação (Mestrado em Processos de Desenvolvimento Humano e Saúde) - Universidade de Brasília, Brasília, 2017.

DIAS, G.; SEGENREICH, D.; NAZAR, B.; COUTINHO, G. Diagnosticando o TDAH em adultos na prática clínica. J. Bras. Psiquiatr., Rio de Janeiro, v. 56, n. 1, p. 9-13, 2007.

GALDEANO, L. E.; ROSSI, L. A.; ZAGO, M. M. F. Roteiro instrucional para a elaboração de um estudo de caso clínico. Rev. Latino-Americana de Enfermagem, Ribeirão Preto (USP), v. 11, n. 3, p. 371-5, 2003.

GRAY, S.; WOLTERING, S.; MAWJEE, K.; TANNOCK, R. The adult ADHD Self-Report Scale (ASRS): utility in college students with attentiondefict/hyperactivity disorder. Peer J, v. 25, n. 2, 2014.

LOPES, R. M. F.; NASCIMENTO, R. F. L.; BANDEIRA, D. R. Avaliação do transtorno de déficit de atenção/ hiperatividade em adultos (TDAH): uma revisão de literatura. Avaliação Psicológica, v. 4, n. 1, p. 65-74, 2005.

MARTINS, J. B. A atuação do psicólogo escolar: multirreferencialidade, implicação e escuta clínica. Psicologia em Estudo, Maringá, v. 8, n. 2, p. 39-45, 2003.

MEINERZ, C. B.; CAREGNATO, C. E. Educação e processos de escolarização no Brasil: perspectivas 
históricas e desafios contemporâneos. Ciências \& Letras, Porto Alegre, n. 49, p. 43-62, 2011.

NEGREIROS, F.; COSTA, T. S.; DAMASCENO, M. A. Medicalização da educação e concepções de professores brasileiros: um estudo descritivo na rede pública de ensino. Clínica \& Cultura, v. 2, n. 1, p. 28$35,2016$.

OLIVEIRA, C. T.; TEIXEIRA, M. A. P.; DIAS, A. C. G. Efetividade de uma cartilha psicoeducativa sobre o TDAH em estudantes universitários. Revista Psicologia: Teoria e Prática, São Paulo, v. 20, n. 2, p. 268-80, 2018.

OLIVEIRA, C. T.; DIAS, A. C. Dificuldades e estratégias de enfrentamento de estudantes universitários com sintomas do TDAH. Revista Psicologia: Teoria e Prática, São Paulo, v. 19, n. 2, p. 269-80, 2017.

OLIVEIRA, E. C.; HARAYAMA, R. M.; VIÉGAS, L. S. Drogas e medicalização na escola: reflexões sobre um debate necessário. Revista Teias, v. 17, n. 45, p. 99-118, 2016.

PLETSCH, M. D. A formação de professores para a educação inclusiva: legislação, diretrizes políticas e resultados de pesquisas. Educar, Editora UFPR, Curitiba, n. 33, p. 143-56, 2009.

PREDIGER, J.; SILVA, R. A. N. Contribuições à Prática do Psicólogo na Educação Profissional. Rev. Psicologia: Ciência e Profissão, v. 34, n. 4, p. 931-39, 2014.

SILVA, M. A. Investigação de Transtorno de Déficit de Atenção e Hiperatividade (TDAH) entre estudantes de odontologia e suas repercussões na destreza manual e desempenho cognitivo. 2014. 152f. Tese (Doutorado em Ciências Odontológicas) Universidade de São Paulo, São Paulo, 2014.

SOUZA, J. C.; LEITE, L. R. C.; DOURADO, J. B.; BASMAGE, J. P. T. Transtorno do Déficit de Atenção e Hiperatividade e qualidade de vida em universitários. Revista Interfaces - Saúde, Humanas e Tecnologia, v. 4, n. 12, p. 101- 6, 2017.

THOMAS, M.; ROSTAIN, A.; CORSO, R.; BABCOCK, T.; MADHOO, M. ADHD in the college setting: Current Perceptions and Future Vision. J Atten Disord, v. 19, n. 8, 2015. 